\title{
Atores locais na implementação da política de qualificação profissional ${ }^{*}$
}

\section{Local actors in the implementation of the policy of professional qualification}

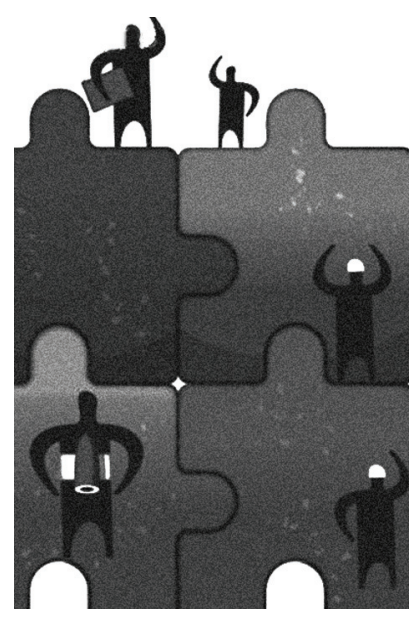

Cristina Almeida Cunha Filgueiras ${ }^{* *}$

Resumo: O artigo examina a execução no nível local de programas de qualificação profissional para trabalhadores urbanos que se encontram em situação de maior precariedade no mercado de trabalho. A oferta de cursos de qualificação ampliou-se desde 2007 no Brasil devido à diversificação dos programas e à conexão com programas de investimento em infraestrutura, os programas de assistência social, transferência de renda, economia solidária, fomento ao empreendedorismo e inserção de jovens. O texto discute a atuação de atores, tais como prefeituras, entidades executoras, agências do Sistema Nacional de Emprego e comissões de emprego.

Palavras-chave: Governo local. Política social. Política de trabalho. Qualificação profissional.

\begin{abstract}
The article discusses the implementation at the local level of professional qualification programs for urban workers. The provision of training courses has broadened since 2007 in Brazil due to diversification of programs and connection with investment programmes on infrastructure, social assistance programs, cash-transfer, solidarity economy, fostering entrepreneurship and insertion of young people. The text discusses the work of actors such as prefectures, executing entities, agencies of the national system of employment and employment committees.
\end{abstract}

Keywords: Local government. Social policy. Labour policy. Professional qualification.

* Versão revisada do trabalho apresentado no $7^{\circ}$ Encontro Nacional da Associação Brasileira de Ciência Política, em 2010.

** Doutora em Sociologia pela École des Hautes Études en Sciences Sociales (EHESS, Paris, França), professora do Programa de Pós-Graduação em Ciências Sociais da Pontifícia Universidade Católica de Minas Gerais, Brasil. E-mail: cfilgueiras@pucminas.br. 


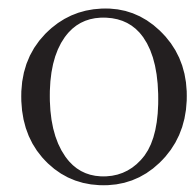
artigo aborda a execução, em nível, local de um eixo importante da Política Nacional de Trabalho, Emprego e Renda, os programas de qualificação profissional para trabalhadores urbanos em situação precária no mercado de trabalho. A oferta de cursos de qualificação para esse segmento ampliou-se no Brasil, em especial nas áreas metropolitanas, devido à diversificação da política de trabalho e sua articulação com o Programa de Aceleração do Crescimento (PAC), as políticas de assistência social, combate à pobreza e transferência de renda e os programas de inclusão social de jovens.

O propósito do artigo é refletir sobre a presença de atores institucionais do nível local, considerando que estes, apesar de envolvidos em diferentes iniciativas de qualificação, raramente são tomados em conta na literatura sobre o tema. Inicialmente são apresentadas as características gerais do mercado de trabalho brasileiro e a situação das políticas de qualificação desde 1995. Em seguida, são mencionadas as conexões de ações de qualificação com programas sociais focalizados sobre segmentos da população em situação social vulnerável e examinada a presença de atores do nível local na sua implementação.

\section{A situação dos trabalhadores e a política de trabalho e emprego}

Enfrentar o problema do desemprego no Brasil é bastante complexo em razão da heterogeneidade do mercado de trabalho. Problemas vividos em todo o mundo, decorrentes do novo paradigma tecnológico, da abertura dos mercados e da globalização, se superpuseram no Brasil, aos problemas estruturais do alto grau de informalização e da precariedade das relações de trabalho, da desigualdade social, das deficiências no sistema de proteção social, do baixo nível de escolaridade da força de trabalho, além da existência de um sistema educacional deficiente e sem articulação com o sistema produtivo (Azevedo, 1997, p. 57).

De 1930 a 1980 aconteceu a estruturação incompleta do mercado de trabalho, havendo o crescimento do segmento organizado nas áreas urbanas brasileiras com o avanço das ocupações homogêneas baseadas nas empresas tipicamente capitalistas, na administração pública e nas empresas estatais, com empregos assalariados regularizados (Pochmann, 2006, p. 124). A partir de 1980 prevaleceu o movimento de desestruturação, caracterizado pela expansão do segmento não organizado do mercado de trabalho urbano, cujas formas principais de ocupação são heterogêneas, isto é, não pertencem às organizações tipicamente capitalistas, administração pú- 
blica e empresas estatais. Observou-se a precarização das ocupações e o enfraquecimento do estatuto do trabalho, mudanças que estão relacionadas à adoção de políticas macroeconômicas de reinserção internacional adotadas pelos governos brasileiros, principalmente nas décadas de 1980 e 1990.

Ocorreram no Brasil, nos anos 1990, a terceirização das atividades e ocupações econômicas, a piora na qualidade dos postos de trabalho e a estagnação relativa dos rendimentos dos trabalhadores. Houve ainda redução percentual da força de trabalho protegida pela legislação. A ação do Estado e as políticas de emprego continuavam dirigidas principalmente à parcela da força de trabalho inserida no setor formal da economia, ampliando a desigualdade entre esse setor da mão de obra e aquele que está na informalidade.

Cardoso Jr. (2005, p. 172) afirma, contudo, que paralelamente ao processo de desestruturação do mercado de trabalho foram se estabelecendo mecanismos públicos de emprego que combinam políticas passivas (como o seguro-desemprego) e políticas ativas (como a intermediação e a (re)qualificação de mão de obra). No entanto, até o início dos anos 2000 o impacto desse conjunto de programas sobre a situação dos trabalhadores foi limitado, devido, entre outros fatores, à combinação da heterogeneidade do mercado de trabalho no Brasil com o viés recessivo da política econômica.

Na primeira década de 2000, a retomada do crescimento econômico e dos investimentos produtivos no País repercutiu em aumento de postos de trabalho, redução das taxas de desemprego aberto e de precarização no mercado de trabalho. Ao analisar o período 2004-08, Baltar et al. (2010) observam a elevação do ritmo de crescimento econômico (cerca de 5\% ao ano) com impactos positivos sobre o mercado de trabalho em termos de geração de empregos, redução da taxa de desemprego, melhoria da estrutura ocupacional e de rendimento, além de aumento da proporção de ocupações sob a proteção da legislação trabalhista. No entanto, os autores afirmam não ter sido apenas o crescimento econômico o responsável por tais mudanças, visto que elas resultam também da política de valorização do salário mínimo, da maior fiscalização do cumprimento da legislação trabalhista, das pressões e negociações sindicais, bem como de políticas governamentais nas áreas social e do trabalho.

Apesar das melhoras observadas, persistem problemas estruturais no mercado de trabalho brasileiro, sobretudo a alta rotatividade da mão de obra, a informalidade, o desemprego estrutural e a forte heterogeneidade da estrutura ocupacional. Em 2008 , cerca de $50 \%$ das pessoas ocupadas, com idade de quinze anos e mais, não 
tinham um emprego assalariado e/ou em conformidade com as leis trabalhistas no país (Baltar et al., 2010, p. 14).

O setor de maior destaque em volume de criação de empregos foi o da construção civil, o que foi visto pelo governo e pela sociedade como oportunidade para a ocupação de postos de trabalho pelos setores da população em desemprego crônico, aqueles com dificuldades para iniciar entrada no mercado e com baixa escolaridade. Viu-se ainda uma oportunidade para dar emprego aos beneficiários de programas de assistência social e de combate à pobreza. As perspectivas de crescimento dos investimentos privados e públicos com expectativa de aumento da demanda por trabalhadores qualificados também motivaram o aumento de verbas destinadas pelo governo federal às ações do Ministério do Trabalho e Emprego (MTE) na área de qualificação, o que será abordado mais adiante neste artigo. Os investimentos públicos em qualificação tiveram impulso primeiro do $\mathrm{PAC}$, programa lançado em 2007, composto por investimentos em infraestrutura pública e incentivo ao investimento privado, cujos recursos são destinados às áreas de transportes, energia, saneamento, habitação, recursos hídricos. Em seguida surgiu o programa Minha Casa Minha Vida, de produção de moradia para setores de baixa renda lançado em 2009, para o qual também se preconizou a articulação com as ações de qualificação.

\section{A qualificação profissional no sistema público de emprego desde 1995}

Uma política de qualificação profissional se classifica entre as políticas ativas de emprego. De acordo com Azevedo (1997, p. 57), tais políticas

têm um importante papel a cumprir em termos de socialização e integração dos excluídos do mercado de trabalho, de preservação da qualificação da força de trabalho desocupada, de geração de atividades à margem do setor moderno da economia, mas capazes de garantir a sobrevivência de indivíduos e comunidades e, em alguns casos, de elevação dos padrões de organização e consciência social e, portanto, de cidadania.

Não é tarefa simples definir o que é qualificação. Trata-se de um conceito multifacetado, existindo várias acepções para o termo. Além disso, como alertam Leite e Posthuma (1996), analisar as práticas envolvidas nesse âmbito exige compreender qualificação como uma construção sociocultural. As ações de formação 
se referem aos ambientes dos locais de trabalho nas empresas, mas também às cadeias produtivas e a elementos comportamentais gerais dos trabalhadores. A qualificação desempenha funções sociais mais amplas do que apenas o aprendizado de conhecimentos e habilidades necessárias ao desempenho do trabalho. Ademais, o campo da qualificação acompanha a divisão do trabalho e a segmentação do mercado de trabalho.

No Sistema Brasileiro de Proteção Social (Cardoso Jr. e Jaccoud, 2005), a qualificação para o trabalho se inclui entre as políticas organizadas com base no eixo emprego e trabalho juntamente com a Previdência Social; previdência e benefícios de servidores públicos; políticas de apoio ao trabalhador (seguro-desemprego, intermediação de mão de obra, qualificação profissional, crédito para geração de emprego e renda, benefícios específicos dirigidos aos servidores públicos); políticas ligadas à organização agrária e à política fundiária. Incluem-se ainda no eixo emprego e trabalho as ações dirigidas aos trabalhadores desempregados, àqueles pertencentes ao setor informal da economia, isto é, trabalhadores sem carteira, os autônomos, os trabalhadores não remunerados e que produzem para autoconsumo. ${ }^{1}$

As origens do sistema público de emprego no Brasil remontam à década de 1960. Porém somente nos anos 1970, com a unificação dos recursos do PIS/Pasep e a efetivação do Sistema Nacional de Emprego (Sine), a intermediação de mão de obra, a qualificação profissional, (re)colocação e assistência financeira aos desempregados tornaram-se significativos (Cardoso Jr., 2005). Na década de 1980 o fato mais destacado foi a instituição do seguro-desemprego em 1986, o qual em seus anos iniciais teve uma cobertura muito baixa. Apenas após a instituição do Fundo de Amparo ao Trabalhador (FAT), em 1990, puderam existir de modo mais consistente as políticas básicas de um sistema público de emprego no Brasil.

O FAT tornou-se a primeira fonte de custeio para a gestão e implementação dos programas de seguro-desemprego, intermediação de mão de obra e qualificação profissional, além do financiamento de ações voltadas para a geração de emprego e renda via concessão de microcrédito. $O$ fundo destinou recursos aos planos nacionais de qualificação, os quais serão apresentados a continuação. Antes, contudo, é necessário advertir que a política de qualificação profissional no Brasil é muito mais ampla do que examinamos nestas páginas. Abordar de modo completo a po-

1. Os outros três eixos do sistema classificados pelos autores são "assistência social e combate à pobreza", "direitos constitucionais de cidadania social", que inclui educação fundamental e saúde; e "infraestrutura social", que abrange habitação e saneamento. 
lítica exigiria mencionar os sistemas de ensino universitário e técnico, bem como as iniciativas do âmbito empresarial (Manfredi, 2002; Leite e Posthuma, 1996). Porém essa não é a intenção do presente texto, ao qual interessam em especial as iniciativas públicas de qualificação dos anos recentes dirigidas ao segmento de trabalhadores que não têm acesso aos demais sistemas de formação.

\section{Plano Nacional de Qualificação Profissional (Planfor)}

Com a criação do Planfor em 1995, o governo brasileiro visava contrapor-se ao movimento de desqualificação da mão de obra resultante das alterações na organização produtiva e da introdução de novas tecnologias de informação que exigiam um trabalhador mais qualificado e flexível. Segundo Moretto (2007, p. 165-166), o plano tomou como uma premissa que o desemprego é consequência do processo de reestruturação produtiva combinado à baixa qualificação do trabalhador brasileiro. Além dos beneficiários do seguro-desemprego, o Planfor pretendia atender os trabalhadores desempregados ou com risco de perder o emprego, os beneficiários de programas de geração de emprego e renda, os trabalhadores autônomos, os microprodutores do setor informal e os segmentos populacionais em risco social.

O Planfor foi implementado de modo descentralizado, via comissões estaduais e municipais, tendo como principais instrumentos institucionais os Planos Estaduais de Qualificação (PEQs), que contemplavam ações de qualificação profissional elaboradas e geridas pelas Secretarias Estaduais de Trabalho, sob homologação das Comissões Estaduais de Trabalho, a quem cabia a articulação com as Comissões Municipais (Barbosa e Porfírio, 2009, p. 7). Os cursos de qualificação, contratados pelos governos estaduais, multiplicaram-se ao longo da segunda metade da década de 1990. No período 1995 a 2001, o Planfor qualificou mais de 15 milhões de pessoas, com um custo de mais de 2 bilhões de reais, mobilizando centenas de entidades executoras públicas e privadas.

Muitos problemas foram identificados na implementação do plano, entre as quais a baixa qualidade e a curta duração dos cursos; a escassa integração com as demais políticas públicas, sobretudo aquelas vinculadas às áreas de educação e de trabalho e renda; a fragilidade do sistema de monitoramento e avaliação dos cursos; as ações minimalistas do Estado, concentrando-se apenas na orientação e no financiamento do Plano; as irregularidades no uso dos recursos; a fragilidade das comissões estaduais e municipais como espaços de articulação dos segmentos de empre- 
sários, trabalhadores e governo para o exercício das funções de elaboração, acompanhamento e fiscalização da política de qualificação profissional (Barbosa e Porfírio, 2009, p. 8). Outra crítica frequente feita ao plano se refere à privatização da educação profissional com a contratação de uma variedade de entidades privadas para executar os cursos, sendo que muitas delas não possuíam experiência para ministrá-los. Ademais, a decisão sobre os cursos de qualificação esteve mais atrelada à oferta existente nas entidades de formação do que à demanda gerada por empresas ou trabalhadores.

De acordo com Souza (2009, p. 169), a formação oferecida pelo Planfor não atendeu às demandas do mercado de trabalho, porém cumpriu as funções de assistir temporariamente o trabalhador e, assim, reduzir a pressão sobre esse mercado. Por sua vez, Oliveira (2010) considera que o desenvolvimento de uma oferta pública de qualificação para os pobres, como aquela do Planfor, foi um dos fatos destacados na esfera da formação profissional desde meados dos anos 1990: “o poder público cria o programa de ações de qualificação, na modalidade de formação básica, localizado no Ministério do Trabalho e Emprego, cuja função era o repasse de recursos a organizações civis, sindicatos e instituições da área de educação, com o objetivo de ocupar a mão de obra desempregada e mais vulnerável socialmente, em atividades marginais de geração de renda e empregos desqualificados". Posteriormente, continua a autora, o plano foi "reformulado no sentido de definir carga horária mínima, estabelecer os desempregados como público prioritário, e limitou sua execução aos governos estaduais e municipais, através de convênios. Permaneceu, contudo, nos marcos do conceito de qualificação para pobres, com forte conotação assistencial por parte das instituições gestoras dos recursos e executoras" (Oliveira, 2010, p. 32).

Em 2003, no início do primeiro governo Lula, o Planfor foi substituído por outro plano. Houve ajustes, mas os fundamentos da política de qualificação não foram modificados no que se refere a financiamento pelo fundo federal e outras fontes da União principalmente, execução descentralizada por organismos privados ou públicos contratados caso a caso ou por blocos de cursos por território.

Plano Nacional de Qualificação (PNO)

A percepção, pelos agentes sociais e por especialistas, de que parte significativa dos planos nacionais de qualificação cumpre papel mais assistencial que de 
ampliação de oportunidades no mercado de trabalho se aprofundou com a adoção do PNQ. Entre as novidades trazidas pelo plano estavam o aumento da carga horária dos cursos (foram estabelecidos carga horária mínima e conteúdos pedagógicos específicos), a ampliação do controle e monitoramento e a busca de maior integração com outras políticas. O plano introduziu a noção de qualificação social, passando a se referir a qualificação social e profissional. A qualificação social consistiria em cursos destinados a jovens e adultos, independente de escolaridade, que visam despertar o interesse pelo trabalho e preparar para o desempenho de tarefas básicas e de menor complexidade de uma profissão ou de um conjunto de profissões. Fazem parte desse grupo os programas de capacitação ligados às ações visando a geração de renda e a inclusão do indivíduo.

O PNQ previu três modalidades de execução: 1) os Planos de Qualificação Territorial (PlanTeQ), realizados em convênio com os governos estaduais e, desde 2004, também com municípios ou consórcios intermunicipais; 2) os Projetos Especiais de Qualificação (ProEsQ), com o propósito de desenvolver metodologias em qualificação profissional, executados em convênio com instituições de educação profissional e centrais sindicais; e 3) os Planos Setoriais de Qualificação (PlanSeQ), para atender demandas de qualificação em cadeias produtivas e setores específicos de atividade econômica e arranjos produtivos locais, executados em parceria com entidades públicas e privadas.

Dentro de um conjunto muito vasto de potenciais beneficiários, o PNQ estabelece a prioridade para os trabalhadores desocupados pertencentes aos grupos mais vulneráveis econômica e socialmente (por fatores como baixa renda, baixa escolaridade e/ou discriminação de gênero, raça/etnia, idade, deficiência). Veremos a seguir como esse público, que é também o público prioritário das ações de assistência social e transferência de renda, é contemplado dentro dos planos de qualificação profissional e em especial do PlanSeQ.

\section{Vínculos da qualificação com outras políticas públicas}

É conhecida a insuficiente conexão entre os programas do Sistema Público de Emprego e demais programas voltados para a qualificação profissional dos trabalhadores existentes em várias iniciativas governamentais. Tal situação persiste após mais de quinze anos de ações executadas no âmbito do FAT. Além disso, continuam sendo criados programas de qualificação em diferentes ministé- 
rios, sem que, contudo, a política de qualificação se perceba como um conjunto coerentemente estruturado.

As políticas tradicionais do sistema público de emprego, entre elas a de qualificação, não são eficazes para enfrentar a situação de heterogeneidade e precariedade do mercado de trabalho brasileiro (Cardoso Jr., 2005, p. 171). Este seria um dos fatores explicativos da estreita vinculação desenvolvida nos anos recentes entre aquele sistema e as políticas de assistência social. As ações do eixo de política com base no trabalho associam-se às políticas do eixo da assistência social e aos programas de transferência condicionada de renda e de combate à pobreza. Tal conexão está muito evidente na relação entre PlanSeQ, Bolsa Família (programa de transferência condicionada a renda, instituído em 2003) e PAC.

Os cursos de qualificação estão entre as ações complementares que buscam contribuir para a ampliação das oportunidades de inclusão dos beneficiários do Bolsa Família. Dentro das estratégias traçadas pelo governo federal para as ações complementares encontra-se o Plano Setorial de Qualificação e Inserção Profissional para os beneficiários do Bolsa Família, ou PlanSeQ do Bolsa Família. A articulação federativa para sua execução envolve no plano local as Secretarias de Trabalho ou congêneres ou gestor das agências de intermediação de mão de obra e as Secretarias de Assistência Social e gestores do Bolsa Família (Brasil. MTE/MDS, [2008].

As entidades executoras dos cursos do PlanSeQ são selecionadas por meio de edital de chamada pública divulgado pelo TEM e, em seguida, contratadas pelo governo federal. As metas de cobertura a serem cumpridas em cada cidade são definidas pelo Ministério do Desenvolvimento Social e do Combate à Fome (MDS), a quem cabe também a definição dos potenciais beneficiários. O ministério classifica as famílias que recebem o Bolsa Família com base no Índice de Desenvolvimento Familiar (IDF) ${ }^{2}$ e dá prioridade àquelas com menor índice para se inscrever nas ações de qualificação. As famílias selecionadas são comunicadas por meio de carta enviada pelo gestor federal, informando sobre a possibilidade de inscrever um dos seus membros em um curso. A partir daí entram em cena os governos municipais e as entidades executoras. Posteriormente as ações definidas no âmbito do

2. O IDF foi criado para uso na focalização dos programas sociais e no monitoramento e avaliação dos programas sociais. O índice é composto por indicadores de vulnerabilidade decorrente da composição familiar, acesso ao conhecimento, acesso ao trabalho, disponibilidade de recursos, desenvolvimento infantil, condições habitacionais. O IDF de cada família é calculado a partir dos dados registrados no Cadastro Único para Programas Sociais do Governo Federal (CadÚnico). 
PlanSeQ dirigidas ao público do Bolsa Família passaram a chamar-se Programa Próximo Passo, sob responsabilidade dos Ministérios do Trabalho e Emprego, Desenvolvimento Social e Combate à Fome, e do Turismo.

O Próximo Passo é, pois outra denominação dada às ações que já estabelecidas de articulação entre governo federal, empresários e trabalhadores para promover qualificação social e profissional para os beneficiários do Bolsa Família. Realizado como PlanSeQ Construção Civil e Turismo, teve por objetivo garantir a esse público o acesso a vagas de qualificação, reconhecendo que ele tende a ser excluído ou ficar em segundo lugar na ocupação das oportunidades de qualificação. Em 2009 e 2010, o programa ofereceu cursos para ocupações da construção civil, setor impulsionado principalmente pelas obras do PAC, do programa Minha Casa Minha Vida e programas da área de turismo. ${ }^{3}$

Verifica-se, portanto, que o aumento na oferta de cursos ocorrido no Brasil desde 2007 decorre das várias frentes programáticas do governo federal que contemplam ações de capacitação e qualificação para o trabalho e em especial daqueles programas orientados aos segmentos atendidos em programas de combate à pobreza e mais vulneráveis no mercado de trabalho. Porém a oferta também inclui iniciativas de alguns governos estaduais e municipais, que não são consideradas neste artigo.

A partir de 2003 o governo federal estabeleceu ainda duas novas políticas que incluíram programas com cursos de qualificação e capacitação. A primeira delas é a política de economia solidária; a segunda é a política para a juventude voltada, entre outros temas, para inserir no mercado de trabalho os jovens de baixas renda e escolaridade. No âmbito da política para a juventude, pelo fato de incluir ações de qualificação profissional e social, merece ser mencionado o Programa Nacional de Inclusão de Jovens - Projovem, dirigido a jovens de 15 a 29 anos em situação de vulnerabilidade social, que tenham terminado a quarta série, não tenham concluído o Ensino Fundamental e não tenham emprego com carteira assinada. Beneficiários do Projovem nas localidades onde existem outros cursos de qualificação dirigidos à população em vulnerabilidade social são encaminhados para tais ações pela equipe do Centro de Referência da Assistência Social (Cras).

3. As vagas do Próximo Passo se distribuíram entre cursos no setor da construção civil em 249 municípios nas regiões metropolitanas e capitais e cursos no setor de turismo em 22 capitais. Na construção civil são ofertados cursos de pedreiro, pintor, eletricista, encanador, mestre de obras, entre outros. No turismo, cursos de garçom, cozinheiro, padeiro, mensageiro, camareiro e auxiliar de eventos, entre outros. 
A partir do que foi apresentado, podemos afirmar que durante a última década a área de qualificação profissional orientada aos trabalhadores socialmente mais vulneráveis passou por diversas inovações. Além disso, ocorreram esforços de articulação entre cursos de qualificação, programas de investimento em infraestrutura urbana e os programas de transferência de renda.

\section{Visões críticas sobre pressupostos da política pública de qualificação}

Antes de nos referirmos aos atores locais dos programas de qualificação, consideramos necessário destacar críticas feitas por estudiosos dos temas sociais ao enfoque geral que embasa políticas públicas recentes no Brasil no âmbito do trabalho.

Como já foi dito, os planos nacionais padecem de várias limitações: falta de sintonia entre a qualificação requerida e os cursos disponíveis; disparidade entre o volume de treinandos e a capacidade de absorção da mão de obra qualificada; desarticulação entre oferta de qualificação e demais instrumentos da política de emprego, por exemplo, o crédito. A maior limitação da política operacionalizada por meio desses planos consiste, na opinião de Souza (2009, p. 172-173), em não reconhecer que a causa principal do desemprego não é a falta de qualificação do trabalhador, mas a lógica da estrutura produtiva. Outra crítica feita aos programas de capacitação e às políticas de emprego no conjunto é a adoção da lógica do empreendedorismo, com o propósito de transformar o trabalhador em autônomo e dono do próprio negócio, sem que as condições e apoios necessários lhe sejam oferecidos.

Na década de 2000, o padrão adotado por grande parte das intervenções públicas passou a ser o de ajudar a aumentar a empregabilidade dos trabalhadores, para aqueles que ainda podem vir a entrar no mercado formal e, por outro lado, fomentar o empreendedorismo naqueles setores que dificilmente encontrariam oportunidade em postos de trabalho formal. Empregabilidade e empreendedorismo tornaram-se estratégias para encobrir novas e velhas fragilidades no mercado de trabalho. Silva (2003) considera que, além de substituírem o conceito de informalidade, tais propostas refletem um novo modo de exploração capitalista e dominação no mundo do trabalho que se baseia na adaptação ao desemprego, ao risco e à insegurança. Esse autor, como outros críticos dos programas de qualificação que visam aumentar a empregabilidade do trabalhador, considera que tais iniciativas governamentais encobrem os problemas que a sociedade enfrenta para a geração 
de emprego e renda devido à estrutura econômica existente e à redução dos postos de trabalho formais. $\mathrm{O}$ uso da noção de empregabilidade nas políticas públicas teria por consequência transferir para o trabalhador a responsabilidade de estar desempregado. Assim, no novo contexto produtivo onde a reestruturação é permanente, "a própria efetividade do programa de qualificação é questionada, na medida em que as empresas tendem a não privilegiar a qualificação de mão de obra. Ou seja, a qualificação funciona como discurso ideológico, ao oferecer cursos para os desempregados, acaba por transferir a responsabilidade para a vitima, pois se o trabalhador não conseguir trabalho mesmo com a ajuda de um curso de qualificação, o fracasso é somente dele" (Deddeca apud Moretto, 2007, p. 168).

Frente à situação do mercado de trabalho e às suspeitas com relação aos efeitos provocados pela qualificação, ganha relevância a pergunta: "Qualificar para quê?" Souza avança os seguintes elementos de resposta:

A política de qualificação, ao privilegiar a condição de vulnerabilidade na escolha do público-alvo, depara-se com trabalhadores com baixa escolaridade e posição desvantajosa no mercado de trabalho. Tal opção não é aleatória. São estes que se submetem a trabalhos precários e desprotegidos. Logo, se a qualificação oferecida por esta política não atende às demandas do mercado, é na lógica da assistência que vamos encontrar resposta à pergunta: "qualificar para quê?". Não por acaso os critérios de elegibilidade para inserção, tanto no Planfor quanto no PNQ são praticamente os mesmos utilizados pela política de assistência social. Não por acaso as comissões de emprego são, em muitos lugares, alocadas nas secretarias responsáveis por esta política. (Souza, 2009, p. 174)

A autora sugere que a política de qualificação do trabalhador contribui para dar legitimidade às ações estatais frente ao desemprego e, ao mesmo tempo, serviria como recurso político para os governos subnacionais: "Nos estados, o ganho político está na relação com as executoras. A gestão de recursos do FAT, para a aplicação dos antigos Planos Estaduais de Qualificação (PEQs) e atuais Planos Territoriais de Qualificação (Planteqs), os coloca em condição privilegiada para negociar com diversos atores, entre os quais sindicatos, "Sistema S" e ONGs. Quanto aos municípios, mais próximos dos treinandos, a despeito das dificuldades na relação com os governos estaduais, o maior benefício é a possibilidade de apresentar alternativas à problemática do desemprego, sem onerar o próprio orçamento. Como é no município que o trabalhador vive, é dele que mais facilmente cobra ações, é nele que busca soluções. O financiamento por meio do FAT faz da quali- 
ficação um excelente negócio. Os cursos representam ações concretas frente ao desemprego, e os gestores não deixam de tirar vantagens políticas" (Souza, 2009, p. 174).

As colocações acima nos remetem à implementação da política de qualificação no nível local. Quais são as motivações e interesses dos atores locais em envolver-se na execução dos projetos de qualificação? Quais atribuições assumem? Como se desempenham?

\section{Os atores locais da execução dos programas de qualificação}

Em geral, os estudos sobre os planos nacionais de qualificação estão voltados para a avaliação global ou para análise do desempenho em alguns estados, sendo raramente considerado o papel dos governos municipais e outros atores locais nos programas que incluem cursos de qualificação para os trabalhadores.

O campo das políticas públicas de emprego acompanha as tendências recentes em outros âmbitos de política social no Brasil, com a descentralização para o nível municipal e a focalização nos segmentos considerados mais vulneráveis socialmente. O papel dos governos locais está associado à descentralização iniciada após a Constituição de 1988. Desde então, em um processo gradual e não linear, verificou-se o repasse de atribuições, responsabilidades e recursos do governo federal aos estados e municípios para o desempenho de políticas públicas. Contudo, em cada uma das áreas de política pública a União, os estados e os municípios articulam-se de maneira diversa (Almeida, 2005; Arretche, 2004).

Em algumas políticas públicas é evidente o papel indutor exercido nos últimos anos pelo governo federal para a estruturação do setor nas administrações municipais. O formato de muitos programas nacionais indica a expectativa de contar com capacidades operacionais e participação ativa dos governos locais na sua execução, bem como no financiamento de alguns dos seus componentes e no desenvolvimento de iniciativas próprias. Um exemplo é a implantação do Sistema Único de Assistência Social (Suas) e a manutenção do CadÚnico, ${ }^{4}$ bem como a execução dos programas de transferência de renda, principalmente o Bolsa Família (Filgueiras e

4. O CadÚnico foi instituído 2001 para identificação e registro, em cada um dos municípios do país, das famílias em situação de pobreza potencialmente beneficiárias dos programas sociais. O cadastro é ali- 
Caetano, 2008). É importante mencioná-los aqui porque os programas de qualificação profissional dirigidos à população em situação de vulnerabilidade social também se apoiam no funcionamento de tais mecanismos.

\section{Governos municipais}

As prefeituras podem estabelecer convênios com o MTE para desenvolver ações de qualificação e de intermediação de mão de obra. Algumas delas são responsáveis por unidades do Sine ou tem agências próprias de intermediação. Além disso, há prefeituras de capitais dos estados e cidades de maior porte que têm iniciativas próprias de formação para o trabalho e oportunidades de geração de renda, chegando a constituir um programa municipal de qualificação unificando ações desenvolvidas por diversos órgãos da administração local destinadas a pessoas em condições de vulnerabilidade social beneficiárias dos programas sociais e desempregados cadastrados no Sine. Deve ser mencionado também que há estados da federação que possuem programas de qualificação desenvolvidos com a participação das prefeituras.

$\mathrm{Na}$ execução do Planfor, as prefeituras não tinham papel claramente estabelecido, sendo os governos estaduais os responsáveis principais. Já o PNQ incluiu atribuições para os governos municipais. Uma resolução do MTE de 2005 autorizou municípios com mais de 300 mil habitantes a estabelecer convênios diretamente com o ministério para a proposição e execução de projetos de qualificação sem se submeter a comissões estaduais. Posteriormente, também os municípios com mais de 200 mil habitantes passaram a ter possibilidade de celebrar convênios para executar diretamente a qualificação profissional.

Já foi mencionado que nos programas de qualificação conectados às políticas de transferência de renda, assistência social e política para jovens, as administrações municipais desempenham diversos papéis. Com relação ao PlanSeQ para o público do Bolsa Família, as prefeituras foram convocadas a cumprir as metas decididas pelo MDS. Em todo o país houve grande dificuldade para que o plano se efetivasse no âmbito local e para que as metas de cobertura das vagas nos cursos fossem minimamente atingidas. Foram realizados constantes apelos nesse sentido pelo

\footnotetext{
mentado pelos técnicos dos governos municipais com informação coletada junto às famílias. Periodicamente, o MDS exige que as prefeituras atualizem os dados dessa base de informações.
} 
governo federal a prefeitos e equipes municipais, para que mobilizassem a população beneficiária do Bolsa Família para os cursos.

A interação com os beneficiários cabe, no PlanSeQ, às Secretarias Municipais de Assistência Social, particularmente às equipes do serviço de proteção básica e do Bolsa Família, ainda que não sejam elas as responsáveis diretas pela entrega do serviço de qualificação. A participação das equipes das prefeituras pode incluir um leque amplo de atividades, tais como: execução de ações de abordagem dos potencialmente beneficiários; entrega de informação às famílias, localização das famílias cujas cartas enviadas pelo MDS foram devolvidas; mobilização, articulação e acompanhamento socioassistencial; adoção de medidas para reduzir a evasão e o abandono dos cursos pelos inscritos; abordagem de beneficiários que abandonem o curso; monitoramento dos cursos; articulação com as agências do Sine para acompanhamento dos treinandos. Não podemos afirmar que em todas as cidades efetivamente as equipes municipais atuem em todo esse elenco de ações ou, ao contrário, que sua participação se restrinja àquelas apontadas.

Sem o intuito de fazer generalizações sobre a dinâmica dos programas de qualificação nas cidades brasileiras ou sobre as interações entre os atores institucionais, reproduzimos a seguir observações de uma técnica da área de Assistência Social da prefeitura de um município de médio porte na Região Metropolitana de Belo Horizonte, que revelam situações vivenciadas pelas equipes locais envolvidas em programas nacionais e estaduais de qualificação: ${ }^{5}$

A entidade executora está sentindo a dificuldade de "encher sala", porque nem todo mundo quer fazer curso para trabalhar em obra. Estamos com a expectativa do Minha Casa Minha Vida e o nosso público precisa ser qualificado para poder ser aproveitado. Com o Planseg, que é todo de cursos de construção civil, [nós da secretaria] fazemos trabalho de formiguinha, de motivação com a população. O Cras também capta o público para os cursos. Os cursos foram decididos sem consulta no município. [...] O ministério só consultou os dados do CadÚnico em Brasília. Mesmo assim temos de realizar o que foi decidido fora, porque senão a prefeitura fica como ineficiente. Nossa cidade recebeu um número grande de vagas para cursos do Planseg. Mas não tem gente para tanto, tiveram de reduzir o número. $\mathrm{O}$ pessoal daqui não quer fazer os cursos. Achávamos que seria bacana o curso de mestre de obras, mas tivemos de tirar porque ele não é para quem tem até $4^{\text {a }}$ série, exige ter mais escolaridade. [...] Tem um

5. O relato é parte do levantamento de dados realizado através de entrevistas, em setembro de 2009 , para estudo desenvolvido por Filgueiras e Pádua (2010). 
desencontro. Em cursos pensados para o público masculino houve grande número de inscrição de mulheres. Os cursos que exigiam o Ensino Fundamental completo não interessaram aos jovens que cumpriam esse requisito, e os adultos que quiseram se inscrever não tinham a formação escolar exigida. São muitos cursos que vieram para a cidade nos últimos meses. Mas tem de cuidar para não sobrepor o que está acontecendo, porque o público é o mesmo. A cidade é uma só, o público é um só, a máquina administrativa é uma só. O ministério contratou uma instituição que veio sei lá de onde, que não conhece nada da cidade, que está perdida. [...] Porque os coordenadores e instrutores são todos de fora, não conhecem aqui. Questionei sobre a capacitação dos instrutores. Houve capacitação? Então nós, da prefeitura, temos de suprir a informação dos instrutoras das entidades. No Planseg, tivemos de colocar uma assistente social nossa para assessorar a entidade.

No município onde trabalha a entrevistada, os técnicos do órgão gestor da política de Assistência Social e do Sine foram informados sobre os cursos que seriam realizados somente quando estes já haviam sido contratados pelos gestores dos programas nos âmbitos federal e estadual. Os órgãos da administração local foram procurados pelas entidades executoras quando elas necessitavam de apoio para encontrar um lugar onde realizar as atividades de alguns cursos ou enfrentaram dificuldades para preencher as vagas oferecidas.

Apesar de circunscritas a um caso específico e segundo a percepção de uma pessoa de apenas uma única instituição, o relato nos permite conhecer mais de perto a execução dos programas, dando concretude ao que aparece de modo genérico e distante nos planos governamentais. Além disso, ainda que possa conter vieses devido ao lugar institucional que ocupa a entrevistada, as informações e opiniões manifestadas evidenciam problemas reais na articulação entre níveis federal, estadual e municipal, bem como entre órgãos da administração municipal, e entre os órgãos públicos e as entidades privadas contratadas para prestação do serviço aos beneficiários dos programas.

Sine

O Serviço foi criado para possibilitar a inserção e a reinserção do trabalhador no mercado de emprego mediante intermediação, qualificação e divulgação de informações, além de apoio a iniciativas de geração de emprego e renda. Seu propósito principal é contribuir para melhorar as condições de acesso, permanência e retorno do trabalhador ao mercado de trabalho. 
De acordo com o PlanSeQ, é atribuição do Sine realizar as ações de divulgação dos cursos de qualificação contratados e encaminhamento de pessoas para inscrição; inscrição dos beneficiários do Bolsa Família nos cursos; incorporação ao cadastro das pessoas que concluíram os cursos; intermediação para a inserção dos egressos em vagas de emprego. Há programas de qualificação nos quais se espera que as equipes do Serviço façam a supervisão dos cursos por meio de uma visita técnica. Os postos e agências do Sine, em sua maioria, não desempenham atividades relativas à busca ativa de pessoas para os cursos de qualificação de nenhum dos programas. Essa tarefa é realizada, quando isso ocorre, pelos técnicos das prefeituras, em geral da área de assistência social.

Existe uma defasagem entre os papéis atribuídos e os efetivamente desempenhados pelo Serviço, a qual se deve a uma série de limitações: escassez de pessoal; excesso de tarefas a cumprir com atribuições em muitas frentes de ação; agências vinculadas às prefeituras que sofrem constantemente os efeitos de mudanças nas administrações municipais, gerando rotatividade de coordenador e de pessoal. Assim como no caso das prefeituras municipais, parece repetir-se para o Sine a suposição dos formuladores da política nacional de que existiria capacidade desses órgãos públicos para desempenhar funções estratégicas na implementação, porém, a realidade local nem sempre corresponde a tal condição.

Comissões municipais de emprego

O Conselho Deliberativo do Fundo de Amparo ao Trabalhador (Codefat) estabeleceu, nos anos 1990, critérios para o reconhecimento das comissões de emprego estaduais, distrital e municipais, consideradas uma condição importante para a participação da sociedade organizada na administração do Sistema Público de Emprego, adequando-se assim à Convenção n. 88 da Organização Internacional do Trabalho. A Comissão Municipal de Emprego é de natureza tripartite e paritária, reunindo representação governamental, dos trabalhadores e dos empregadores e tem por objetivos estabelecer, acompanhar e avaliar a política municipal de emprego, propondo as medidas que julgar necessárias para o desenvolvimento de seus princípios e diretrizes.

O Ministério do Trabalho e Emprego considera a participação da sociedade organizada um componente importante para a execução de suas políticas, dadas as características de ações realizadas de maneira descentralizada, por meio de convênios com estados e parcerias: 
A descentralização aproxima os executores das ações do seu público. Isso é muito positivo. Com efeito, a execução centralizada padece de toda sorte de vícios decorrentes da relativa insensibilidade do executor em relação às demandas do público. Mas a descentralização, que é um passo importante nessa aproximação, deve estar associada à criação de canais institucionalizados de participação dos atores envolvidos, desempenhando variados papéis. Esse foi o objetivo do Codefat ao criar as Comissões de Emprego: possibilitar que, localmente, os atores relevantes tivessem o papel que têm, efetivamente, no plano nacional por meio da participação no próprio Conselho. ${ }^{6}$

O PNQ estabelece que a comissão municipal de emprego atue no levantamento das demandas por qualificação, planejamento, acompanhamento e fiscalização de cursos de qualificação. Contudo, a expectativa de desempenho dessas atribuições corresponde a uma idealização sobre tais instâncias de participação e controle social. Em estudo realizado em municípios mineiros, Filgueiras e Pádua (2010) encontraram comissões fragilmente constituídas, com atuação limitada, algumas inclusive inativas.

Ao examinar as características socioinstitucionais da qualificação profissional em cidades fluminenses, Souza (2009, p. 175) constatou que "independentemente do tamanho e da importância do município, a tarefa de apresentar demandas e acompanhar a qualificação profissional tem sido relegada às comissões locais de emprego [...] Tal equívoco desobriga os governos de estabelecer suportes para esta política".

As comissões não participam na seleção das entidades executora e também não possuem estrutura para realizar diagnósticos, identificar demandas e fazer efetivo controle social. Segundo Barbosa e Porfírio (2009), elas enfrentam as mesmas dificuldades e problemas que conselhos de outras políticas setoriais. São problemas comuns no funcionamento de comissões municipais: absenteísmo nas reuniões principalmente de representantes dos trabalhadores; predomínio da presença de representantes da prefeitura, técnicos de quem depende a dinâmica das comissões; baixa capacidade para levantamento de demandas de cursos, discussão sobre a seleção dos cursos, difusão, fiscalização e controle de programas e cursos.

6. "A criação das Comissões de Emprego". Disponível em: <http://www.mte.gov.br/Trabalhador/ Fat/ComissoesEst/ComissoesEstaduaisEmprego/ACriacaoComissoes/Conteudo/486.asp>. Acesso em: 18 abr. 2011. 


\section{Entidades executoras}

Os cursos da política de qualificação mencionados neste artigo são executados em sua maioria por entidades privadas contratadas depois de chamada pública. As entidades precisam estar previamente habilitadas pelas instâncias definidas na legislação para que possam concorrer às licitações de cursos. Elas não têm atuação fixa em um município. É comum que estejam presentes em muitas frentes de trabalho e atuem simultaneamente em programas de qualificação promovidos por diversos órgãos públicos. Muitas entidades possuem experiência na execução de cursos com recursos do FAT desde a vigência do Planfor.

Apesar da centralidade do trabalho das executoras para a política de qualificação profissional, são pouco conhecidas sua atuação, contribuição e dinâmica de posicionamento no mercado de cursos de qualificação. Existe um mercado estruturado de cursos de qualificação profissional no país, segmentado por tipo de curso e principalmente de acordo com o público e, dentro dele, uma faixa importante do mercado que se refere a cursos de formação dirigidos aos setores mais vulneráveis, financiados com recursos federais, principalmente, mas também recursos dos governos estaduais e municipais. Esta faixa tem atraído entidades especializadas em concorrência pública e que vêm assumindo a responsabilidade pela execução de uma grande quantidade de cursos, como é o caso dos cursos contratados para o PlanSeQ. Um dos aspectos menos conhecidos das entidades executoras são os instrutores. São eles que estabelecem o contato direto com a realidade dos municípios e com os alunos, conhecem mais de perto o que passa na ponta do processo, as dificuldades do trabalho e a dinâmica dos cursos. Em grande parte das executoras os instrutores não pertencem a seu quadro permanente e são contratados por curso, o que leva à grande rotatividade de instrutores nas entidades.

O que foi assinalado aqui sobre os atores locais mostra que há um campo de estudos a ser explorado que diz respeito não apenas à implementação de uma parte da política de qualificação profissional, como também à articulação desta com outros programas nas áreas social e de trabalho.

\section{Considerações finais}

É comum no Brasil a percepção de que os cursos de qualificação dirigidos aos setores socialmente mais vulneráveis dos trabalhadores pobres entregariam uma 
formação de segunda mão, em intervenções de baixa efetividade e escassos resultados obtidos em relação ao propósito de inserção no mercado em condições mais favoráveis que o trabalho precário e/ou de remuneração muito baixa. É necessário, sem dúvida, ter presente que os programas que compõem a atual política de qualificação profissional e social desenvolvem-se em contexto social, econômico e político complexo. Foram apontados no artigo diversos elementos desse contexto. Em primeiro lugar, as características do mercado de trabalho brasileiro, que combina alta proporção de informalidade com postos de trabalho no mercado formal. Em segundo, a realização, desde 2007 de investimentos públicos e privados que têm levado à ampliação da demanda por mão de obra qualificada em alguns setores da economia. $\mathrm{O}$ terceiro é a existência de alta proporção de trabalhadores que precisam ser qualificados para aumentar sua "empregabilidade", porém, por possuir baixa escolaridade, não conseguem aproveitar oportunidades nessa área. O quarto elemento é a existência de um sistema público de trabalho, emprego e renda em constante transformação, com componentes que em muitos aspectos não funcionam articulados. Em quinto lugar, a existência simultânea de vários programas de qualificação profissional em algumas cidades, havendo cidades onde muitos programas e instituições se dirigem ao mesmo público e, de modo separado, buscam o apoio do governo local para a execução das ações. Finalmente, foram mostrados os esforços de articulação da política nacional de qualificação profissional com outras políticas que priorizam o público beneficiário de programas de assistência social, de transferência de renda e de inclusão social, e a política para jovens em situação de risco social.

No rápido panorama apresentado, chamam a atenção as frequentes modificações na política de qualificação desde os anos 1990. Sucedem-se ou superpõem-se órgãos, siglas, atores e atribuições. Devemos recordar que também é desde o final dessa década que a descentralização de programas sociais ganhou força, chegando efetivamente aos municípios. Além disso, deve ser tomada em consideração a reestruturação, desde 2003, da institucionalidade no governo federal com relação à política de assistência social e ao relacionamento entre as unidades federativas envolvidas na sua implementação. Neste contexto movediço, os governos municipais passaram a ocupar uma posição antes inexistente. Sobre eles recaem expectativas, atribuições legais, recursos, incentivos e sanções para que cumpram as funções de execução local de programas federais e estaduais. Além disso, é esperado que as prefeituras tenham suas próprias iniciativas na área de trabalho e geração de renda, de modo a contribuir na inclusão social dos setores pobres e no combate à pobreza. 
No Planfor, os governos estaduais eram os principais responsáveis pelos planos e pelo relacionamento com as entidades executoras. Já no PNQ, os governos municipais parecem estar mais presentes, mas não exatamente na frente do cenário, pois as decisões relacionadas a formulação, cobertura e inclusive tipo de curso e contratação das entidades nem sempre passam pelas administrações municipais.

A oferta de cursos de qualificação se ampliou nos últimos anos, devido à diversificação dos programas federais e estaduais e à conexão do PlanSeQ (posteriormente Próximo Passo) e do PAC com os programas da política de assistência social, transferência de renda, economia solidária e fomento ao empreendedorismo. Os programas aqui destacados são a parte mais frágil na pirâmide de qualificação e estão direcionados a um público que os outros níveis (Sistema $\mathrm{S}$, cursos privados de formação de mão de obra) não querem ou não estão preparados para atender. Seu público-alvo se insere principalmente no segmento do mercado de trabalho pouco estruturado, caracterizado, segundo Cardoso (2005, p. 134), "por uma oferta abundante de mão de obra, compondo a base geral e ampla do mercado de trabalho, com indivíduos em geral de baixa qualificação técnica, sem organização sindical, disputando empregos instáveis — portanto de elevada rotatividade baixo nível de qualificação exigida e prometida, que oferecem poucas perspectivas de ascensão profissional".

As tensões da centralização-descentralização se manifestam de modo muito claro nos programas de qualificação. Os funcionários das Secretarias das prefeituras são acionados para responder às exigências do MTE e do MDS. São procurados também pelas entidades executoras e participam nas ações locais de informação, seleção e encaminhamento para os cursos. Grande parte das administrações locais não é bem organizada para responder às demandas da população e dos demais níveis de governo.

Os atores do nível local - particularmente prefeituras, Sine, entidades executoras, comissões de emprego e beneficiários — participam em um conjunto de iniciativas que apresentam séria defasagem entre os propósitos e os resultados obtidos. Apesar de as ações relacionadas ao PAC e ao PlanSeQ estarem ajudando a relativizar as críticas antigas de que a política de qualificação está desarticulada das demais políticas, a sobreposição de programas públicos é um fato. Em algumas cidades ou territórios mais visados pelas iniciativas do poder público, há multiplicação da oferta de cursos devido aos diversos projetos existentes.

O artigo problematizou a execução de um segmento da política pública de qualificação profissional. Para aprofundar nos temas abordados, são necessárias 
mais pesquisas que lancem luzes sobre os elementos envolvidos na equação programa federal/execução local e a chegada da política na ponta, isto é, os atores institucionais que contribuem para a entrega do serviço aos cidadãos.

\section{Recebido em 26/4/2011 - Aprovado em 13/6/2011}

\section{Referências bibliográficas}

ALMEIDA, Maria Hermínia Tavares de. Recentralizando a federação? Revista de Sociologia e Política, Curitiba, n. 24, p. 28-40, jun. 2005.

ARRETCHE, Marta T. S. Federalismo e políticas sociais no Brasil: problemas de coordenação e autonomia. São Paulo em Perspectiva, São Paulo, v. 18, n. 2, p. 17-26, 2004.

AZEVEDO, Beatriz. Políticas públicas de emprego: tendências e possibilidades. São Paulo em Perspectiva, São Paulo, v. 11, n. 4, p. 47-59, 1997.

BALTAR, Paulo Eduardo de Andrade et al. Trabalho no governo Lula: uma reflexão sobre a recente experiência brasileira. Global Labour University Working Papers, n. 9, maio 2010.

BARBOSA, Rosangela N. C.; PORFIRIO, Mariana I. A qualificação profissional e a comissão municipal de trabalho do Rio de Janeiro. Textos \& Contextos, Porto Alegre, v. 8 n. 2 p. 219-240. jul./dez. 2009.

BRASIL. Ministério do Desenvolvimento Social e Combate à Fome. Ministério do Trabalho e Emprego. Qualificação profissional para beneficiários do Bolsa Família. Orientações técnicas para o acompanhamento do Plano Setorial de Qualificação e Inserção Profissional para os beneficiários do programa Bolsa Família, [2008], 28 p. Disponível em: $<$ http://www. mds.gov.br/backup/sites/banner-internas/praticas-inovadoras-bf-planseq/arquivos/orientacoes_tecnicas_-_secom.pdf>. Acesso em: 18 abr. 2011.

CARDOSO JR., José Celso. A questão do trabalho urbano e o sistema público de emprego no Brasil contemporâneo: décadas de 1980 e 1990. In: JACCOUD, Luciana (Org.). Questão social e políticas sociais no Brasil contemporâneo. Brasília: Ipea, 2005.

; JACCOUD, Luciana. Políticas sociais no Brasil: organização, abrangência e tensões da ação estatal. In: JACCOUD, Luciana (Org.). Questão social e políticas sociais no Brasil contemporâneo. Brasília: Ipea, 2005.

FILGUEIRAS, Cristina A. C.; CAETANO, André J. Programa federal, execução local: o caso do Bolsa Família. In: ; FARIA, Carlos Aurélio P. Governo local e políticas urbana e social na América do Sul. Belo Horizonte: Editora PUC-Minas, 2008. 
FILGUEIRAS, Cristina A. C.; CAETANO, André J.; PÁDUA, Karla C. Estudo de avaliação de implementação dos cursos de qualificação profissional/Projeto Usina do Trabalho. Relatório final. Ipead-UFMG/Sedese. Pesquisa de avaliação de implementação e Pesquisa de egressos dos cursos de qualificação profissional no âmbito da Política Estadual de Qualificação. Belo Horizonte, 2010.

LEITE, Márcia de Paula; POSTHUMA, Anne Caroline. Reestruturação produtiva e qualificação: reflexões sobre a experiência brasileira. São Paulo em Perspectiva, São Paulo, v. 10, n. 1, 1996.

MANFREDI, Silvia M. Educação profissional no Brasil. São Paulo: Cortez, 2002.

MORETTO, Amilton J. O sistema público de emprego: uma construção inacabada. Tese (Doutorado) - Unicamp, Campinas, 2007.

OLIVEIRA, Lúcia M. de. Trabalho, sem pecado original. Pensar BH/Política Social, Belo Horizonte, n. 25, p. 29-32, mar. 2010.

POCHMANN, Márcio. Mercado geral de trabalho: o que há de novo no Brasil? Parcerias Estratégicas, Brasília, v. 22, p. 121-144, 2006.

SILVA, Luiz Antônio Machado da. Da informalidade à empregabilidade (reorganizando a dominação no mundo do trabalho). Cadernos CRH, Salvador, n. 7, p. 81-109, jul./dez. 2003.

SOUZA, Fátima V. F. de. De Planfor a PNQ: permanecem os dilemas da política de qualificação profissional. Serviço Social \& Sociedade, São Paulo, n. 97, p. 166-167, jan./mar. 2009. 